\title{
Epidemiological Investigation of an Outbreak of Acute Encephalitis Syndrome (AES) in Malda District of West Bengal, India
}

Bhaswati Bandyopadhyay ${ }^{1 *}$, Debjit Chakraborty ${ }^{2}$, Sibarjun Ghosh ${ }^{3}$, Raghunath Mishra4, Mehebubar Rahman ${ }^{1}$, Nemai Bhattacharya $^{1}$, Soleman Alam ${ }^{5}$, Amitabha Mandal ${ }^{5}$, Anjan Das 6 , Abhijit Mishra ${ }^{6}$, Anand K Mishra ${ }^{7}$, Arvind Kumar ${ }^{7}$, Surya Haldar ${ }^{1}$, Tarun Pathak ${ }^{6}$, Nepal Mahapatra $^{6}$, Dilip Kumar Mondal ${ }^{5}$, Dipankar Maji ${ }^{8}$ and Nandita Basu ${ }^{1}$

${ }^{1}$ Calcutta School of Tropical Medicine, India

${ }^{2}$ Integrated Disease Surveillance Programme, State Surveillance Unit, India

${ }^{3} R$ G Kar Medical College, India

${ }^{4}$ Institute of Post Graduate Medical Education and Research Institute, India

${ }^{5}$ District Health Officials, Malda District, India

${ }^{6}$ Malda Medical College, India

${ }^{7}$ Sree Krishna Medical College, Muzaffarpur, India

${ }^{8}$ Directorate of Health Services, Govt. of West Bengal, India

\begin{abstract}
Background: An unusual outbreak of acute encephalitis syndrome (AES) with high case fatality was reported from Kaliachak- I, II and III Blocks of Malda District of West Bengal in the month of June 2014 affecting 72 children with 34 deaths. The purpose of this study was to investigate the outbreak in the light of epidemiological as well as etiological determinants.
\end{abstract}

Methods: The investigating team collected clinical and epidemiological data from the cases admitted at Malda Medical College and at the Kaliachak BPHC. Different clinical samples, (serum, CSF etc) collected from cases as well as control population were screened for different pathological, biochemical and microbiological parameters. Additionally, the CSF specimens were also processed for the isolation of viruses by inoculating in the chorio-allantoic membrane (CAM) of embryonated chick eggs and intracerebral inoculation of suckling mice. Statistical methods included calculation of proportions (percentages), different test of significance (t-test, chi square etc).

Results: All children were from age group of 9 months to 10 years (median=3, mean=3.73, $S D=1.98$ ) and belonged to low socioeconomic background of litchi growing belt of Malda. Most of the cases were male $(65 \%$ approx). Case Fatality Rate was $47.2 \%$. The main presenting features were sudden onset of convulsions $(100 \%)$ in the early hours of dawn followed by rapid progression to unconsciousness $(100 \%)$ and decerebrate rigidity $(47 \%)$ Fever was present in around one third of cases. Hypoglycaemia and leucocytosis were two predominant features. Clinical samples subjected to molecular and serological testing, were all found negative for known viruses causing acute encephalitis. 3 out of 4 CSF samples produced demonstrable pocks in Chorio allantoic membrane of the embryonated eggs although the pock count varied from 4- 22 per CAM. Significantly low blood glucose level was found in the controls from litchi belt areas as compared to the controls of non-litchi belt areas of Malda.

Conclusion: The evidence gathered so far pointed towards a viral etiology although the causative virus remained unidentified. Hypoglycaemia probably induced by litchi fruit might have aggravated the encephalitis rather than actually causing it.

Keywords: Acute Encephalitis syndrome; Malda; Viral etiology; Pock formation; Hypog

Abbreviations: AES: Acute Encephalitis Syndrome; BPHC: Block Primary Health Centre; CSF: Cerebro Spinal Fluid; CAM: Chorio Allantoic Membrane; JEV: Japanese Encephalitis Virus; SGPT: Serum Glutamate Pyruvate Transaminase; NIMHANS: National Institute of Mental Health and Neuroscience; DNA PCR: Deoxy ribonucleic Acid Polymerase Chain Reaction; RT - PCR: Reverse Transcriptase Polymerase Chain Reaction; HHV-6: Human Herpes Virus 6; CNS: Central Nervous System; MCPA: Methylenecyclopropyl -Alanine; MS: Microsoft; SPSS: Statistical Package for Social Sciences.

\section{Background}

Acute encephalitis syndrome (AES) is a major public health problem in Asia. Acute encephalitis syndrome (AES) is defined as the acute-onset of fever with change in mental status (including symptoms such as confusion, disorientation, coma, or inability to talk) and often with new onset of seizures (excluding simple febrile convulsion) in a person of any age at any time of the year [1]. AES includes illness caused by many infections and most are considered as viral encephalitis
[2]. JE has been considered as leading cause of AES in India [3]. The main etiological agent is Japanese encephalitis virus (JEV), a positive sense single stranded zoonotic flavivirus transmitted by Culex spp. mosquitoes $[4,5]$.

An unusual outbreak of acute encephalitis syndrome (AES) with high case fatality was reported from Kaliachak- I, II and III Blocks

*Corresponding author: Dr. Bhaswati Bandyopadhyay, Associate Professor, In-charge NACO-NRL, Virology Unit, Department of Microbiology, School of Tropical Medicine, 108, C.R. Avenue, Kolkata-700073, West Bengal, India, E-mail: drbhaswati@yahoo.com

Received December 12, 2014; Accepted January 15, 2015; Published January 25,2015

Citation: Bandyopadhyay B, Chakraborty D, Ghosh S, Mishra R, Rahman M, et al. (2015) Epidemiological Investigation of an Outbreak of Acute Encephalitis Syndrome (AES) in Malda District of West Bengal, India. Clin Microbial 4: 181 doi:10.4172/2327-5073.1000181

Copyright: (c) 2015 Bandyopadhyay B, et al. This is an open-access article distributed under the terms of the Creative Commons Attribution License, which permits unrestricted use, distribution, and reproduction in any medium, provided the original author and source are credited. 
of Malda District of West Bengal in the month of June 2014 affecting 72 children with 34 deaths. This was also the time of litchi harvesting in the affected blocks of Malda. We report here our findings of the investigations carried out to find out the possible cause and to describe the clinico-epidemiological features of the AES cases.

The present study being an epidemiological investigation of an outbreak of AES in Malda district hence the methodology could not be planned beforehand. However, based on the clinical and laboratory findings of the affected cases, a planned study of age matched controls was conducted later on

\section{Cases}

Clinically, the presentations indicated Acute Encephalitis Syndrome (AES). Clinical history revealed that all the cases between 9 months to 10 years of age, had been well (according to their parents) and went to bed normally the evening before, but were found to be seriously ill early in the morning with sudden onset generalized seizures, with or without vomiting and/or fever. In many cases, loss of consciousness followed and deteriorated to deep coma and decerebrate posturing, within several hours. Death ensued rapidly in all severely affected cases. Other common features included fever (usually low to moderate grade $<40^{\circ} \mathrm{C}$ ), one or two loose motions, irrelevant talking, combative limb movements or posturing and focal convulsions. Case fatality varied, but was around $50 \%$, but those who recovered did so very rapidly and without any sequelae.

The investigating team studied 72 children (both retrospectively and admitted cases) from age group of 9 months to 10 years (median age $=3$, mean age $=3.73, \mathrm{SD}=1.98$ ) almost all belonging to low socioeconomic background. Most of the cases were male (65\% approx). Almost all cases were from rural areas and the children were visibly malnourished.

The first case occurred on $5^{\text {th }}$ June, 2014. Between $6^{\text {th }}-7^{\text {th }}$ June there was 24 cases with 17 deaths. On $8^{\text {th }}$ June 14 cases were admitted with 3 deaths, $9^{\text {th }}$ June 8 cases with no deaths and between $12^{\text {th }}-19^{\text {th }}$ June 2014, there were 18 cases and 11 deaths (Figure 1,2). No cases were reported on $10^{\text {th }}$ and $11^{\text {th }}$ June, 2014 when there was rainfall and subsequent lowering of environmental temperature. Initially the cases died very rapidly $(11.8 \%)$ within several minutes after admission while $76 \%$ of the deaths occurred within $12 \mathrm{hrs}$ after admission (Figure 3,4). As a result thorough clinical and laboratory investigations could be performed in only a limited number of cases.

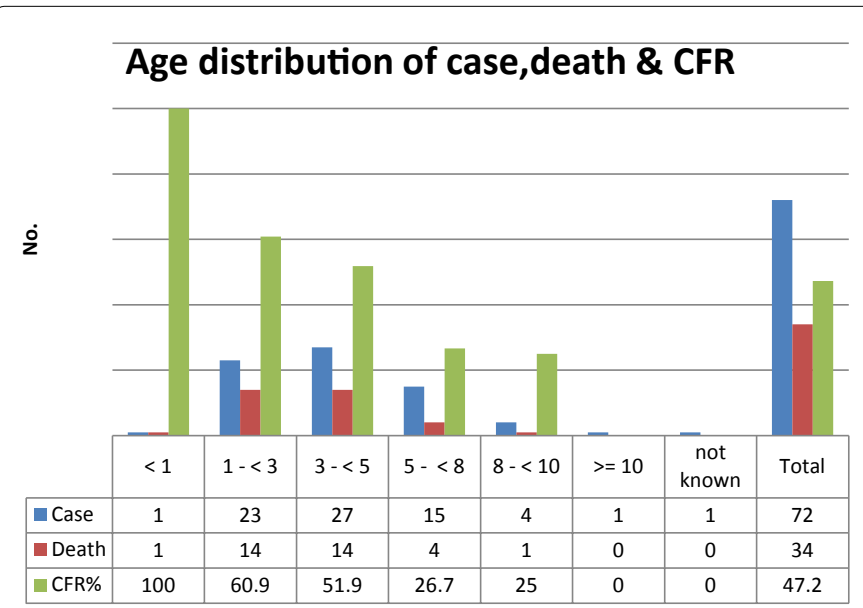

Figure 1: Most of the cases and deaths occurred in below 5 years age groups Case Fatality Rate of under 5 yrs children was much higher (more than twice) compared to that of children above 5 years.

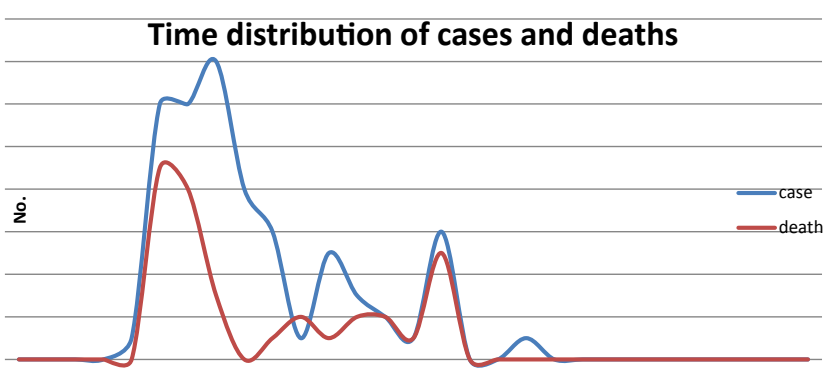

Figure 2: Most of the cases and deaths occurs within first 5 days, however following a decline from $9^{\text {th }}$ June onwards again a small peak was observed on $16^{\text {th }}$ June i.e. on the $12^{\text {th }}$ day of the outbreak.

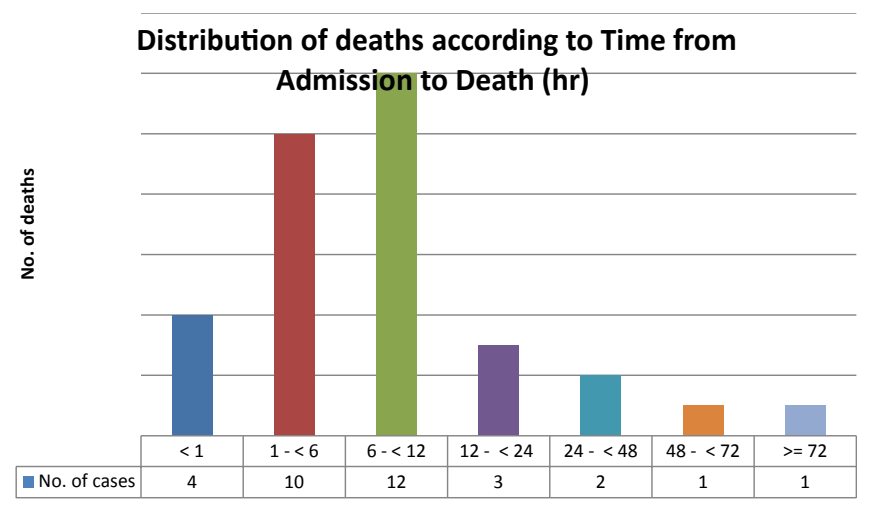

Figure 3: Most of the deaths (26 out of 34 ) occurred within 12 hours of admission almost half of which occurred within 6 hours.

\section{Time distribution of AES cases and deaths}

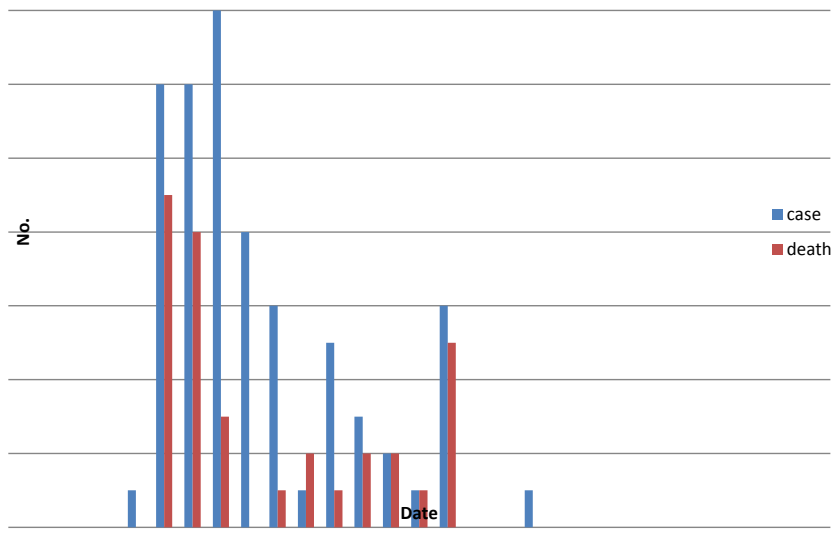

Figure 4: Showing time distribution of AES cases and deaths. Cases starts to occur from $5^{\text {th }}$ June onwards following a period of high temperature and humidity during the Litchi harvesting season in Malda. Most of the cases and deaths occurred during first four days of the outbreak with peak of cases been observed on $8^{\text {th }}$ June. Following this there was a short period of rainfall and cases started to decline thereafter. Strangely a second but small peak was noted on $16^{\text {th }}$ June followed by abrupt decline. Monsoon started in Malda $3-4$ days after the onset of last case i.e during $22^{\text {nd }}-23^{\text {rd }}$ June. By this period Litchi harvesting was also completed.

The main presenting features were sudden onset of convulsions (100\%) usually between the late hours of night and early morning followed by rapid progression to unconsciousness (100\%), decerebrate 
Citation: Bandyopadhyay B, Chakraborty D, Ghosh S, Mishra R, Rahman M, et al. (2015) Epidemiological Investigation of an Outbreak of Acute Encephalitis Syndrome (AES) in Malda District of West Bengal, India. Clin Microbial 4: 181. doi:10.4172/2327-5073.1000181

rigidity (47\%). Fever was present in around one third of cases $(32 \%$ approx.) without any splenomegaly. CSF study could be performed in 4 cases only, as the rapidly deteriorating cases died within hours of admission. All the available CSF reports were normal (cell counts were below 5/cu.mm), except raised pressure. The first few cases died within several hours after onset of symptoms; but later on the cases died after 5 to 6 days. During admission, computed tomography (done in 7 cases) and magnetic resonance imaging scans of the brain (done in 2 cases) showed cerebral oedema only. Strikingly most of the children. ( $72.2 \%$ i.e. 13 out of 18 cases), excluding those screened after a glucose drip, had hypoglycaemia (less than $70 \mathrm{mg} / \mathrm{dl}$ ). Out of those 13 cases, $11(61.1 \%)$ had moderate to severe hypo-glycaemia ( 3 cases i.e. $16.6 \%$ with $31-40 \mathrm{mg} / \mathrm{dl}$ and 8 cases i.e. $44.4 \%$ below 30 $\mathrm{mg} / \mathrm{dl})$.

Hematological investigations revealed leucocytosis, (>15,000/ $\mathrm{cmm})$ in 11 out of 15 cases $(73.3 \%)$ with neutrophil predominance (66.6\%) and normal platelet count.

Biochemical investigations revealed hyponatremia in 3 out of 21 cases, mild raised SGPT (50-100IU/L) ( 5 out of 20 ; i.e. $25 \%$ ), mild raised blood urea ( $\geq 40 \mathrm{mg} / \mathrm{dL}$ ) (11 out of 21 ; i.e. $52 \%$ ), and normal creatinine and potassium. Smears for malarial parasites were negative.

The investigating team could collect serum, whole blood, throat swab and rectal swab samples from 8 cases and CSF samples from 4 cases as the patients were terminally ill. The team also collected serum samples from five convalescent cases and from thirty five asymptomatic contacts among siblings, parents and neighbours of the cases. The serum samples of the cases and contacts and CSF samples of the cases were tested in our Institute for serological evidence (presence of IgM antibody) of Japanese encephalitis, Dengue and Chikungunya which are the commonly occurring arboviral infections of the State of West Bengal but all the samples were negative for those viruses.

The requisite clinical samples were sent to National Institute of Virology, Pune and NIMHANS Bangalore for virological testing. All clinical samples were subjected to Molecular (DNA PCR, RT PCR and Real time RT PCR) and serological testing but were found to be negative for known viruses causing acute encephalitis [5] like Japanese Encephalitis, Nipah, West Nile, chandipura virus, Enteroviruses (Polio, Coxackie, Echovirus and enterovirus 70-72), and Herpes Simplex viruses 1 and 2, Measles virus, Mumps virus, Rubella virus, Dengue, Rabies virus, Chikungunya virus, cytomegalovirus, Varicella zoster virus, JC virus and HHV-6 virus. The samples also tested negative for other Bacterial (Mycobacterium tuberculosis, H. Influenza, $N$. Meningitides, S.pneumoniae), fungal (Cryptococcus neoformans) and protozoal (T. Gondii and Malaria) infections which commonly cause CNS infections

The CSF specimens were also processed in our laboratory for the isolation of viruses by inoculating in the chorio-allantoic membrane of embryonated White Leghorn chick eggs and intracerebral inoculation of suckling mice. An interesting finding was observed- 3 out of 4 CSF samples produced demonstrable pocks in chorio-allantoic membrane of the embryonated eggs. Each sample was inoculated in triplicate and pocks were seen in at least two out of three eggs in all the 3 CSF samples although the pock count varied from 4- 22 per CAM. One CSF sample produced demonstrable sickness in suckling mice on Day 5 (seizures and paralysis and another CSF sample produced only runting of mice. However mice did not develop sickness on second passage and needs further follow-up. On the contrary the pock infected CAM produced lesions on serial passage but the pock count did not increase appreciably

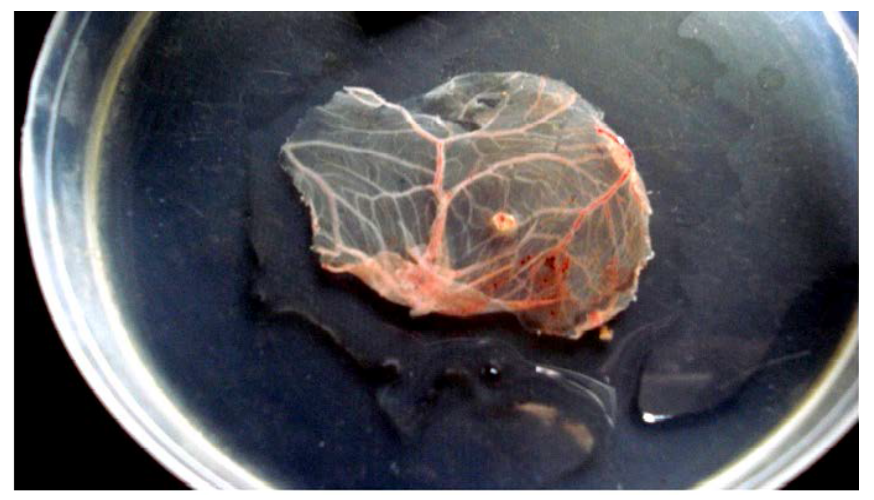

Figure 5: Control-Sterile PBS inoculated in CAM: No pock formation.

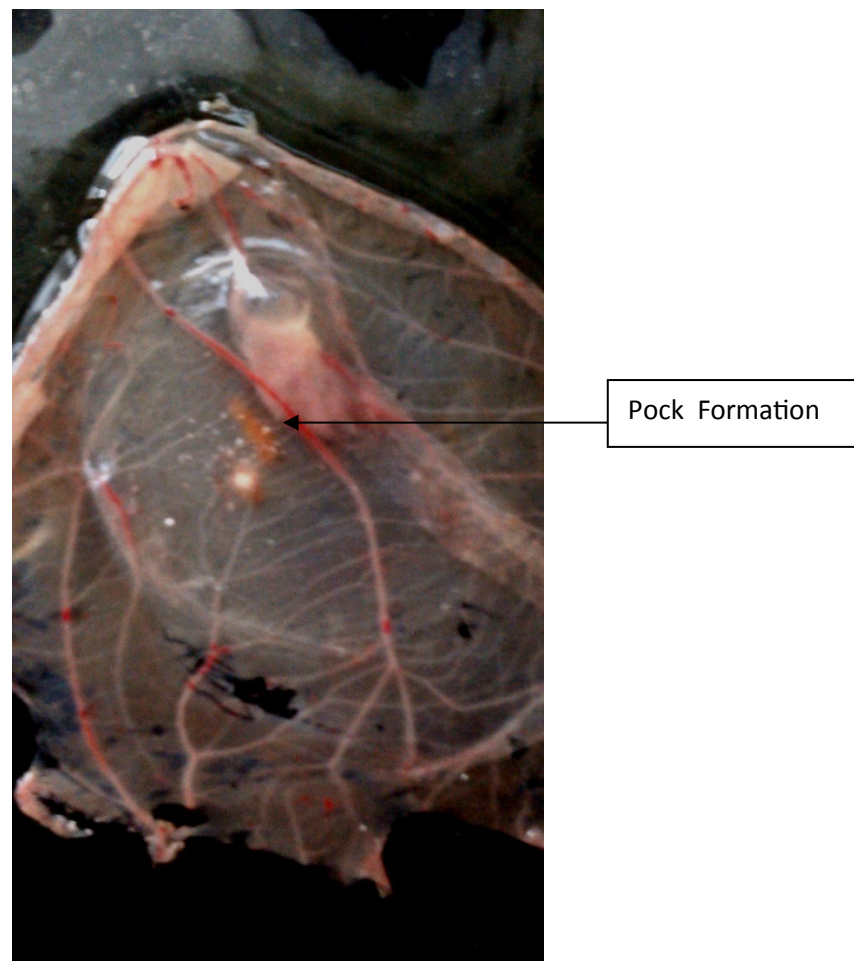

Figure 6: CSF sample collected from Malda inoculated in CAM showing discrete pock formation (Pock Count 20-22).

and needs further follow-up (Figures 5 and 6). One of the reasons could be a very low viral titre in the CSF.

Encouraged by this finding and as the CSF sample size was too small, we collected six new CSF samples from Muzaffarpur, Bihar where a similar outbreak but of greater magnitude was reported. These samples were also processed for the isolation of viruses in chorioallantoic membrane of white Leghorn eggs. Surprisingly, 5 out of six CSF samples produced demonstrable pocks in CAM (Figure 7). This information point towards a viral etiology of the AES cases of Malda and Muzaffarpur.

All cases were treated with $10 \%$ dextrose infusion in addition to standard treatment protocol with anticonvulsants, anti-edema measures like $20 \%$ mannitol, antipyretic (acetaminophen) along with 


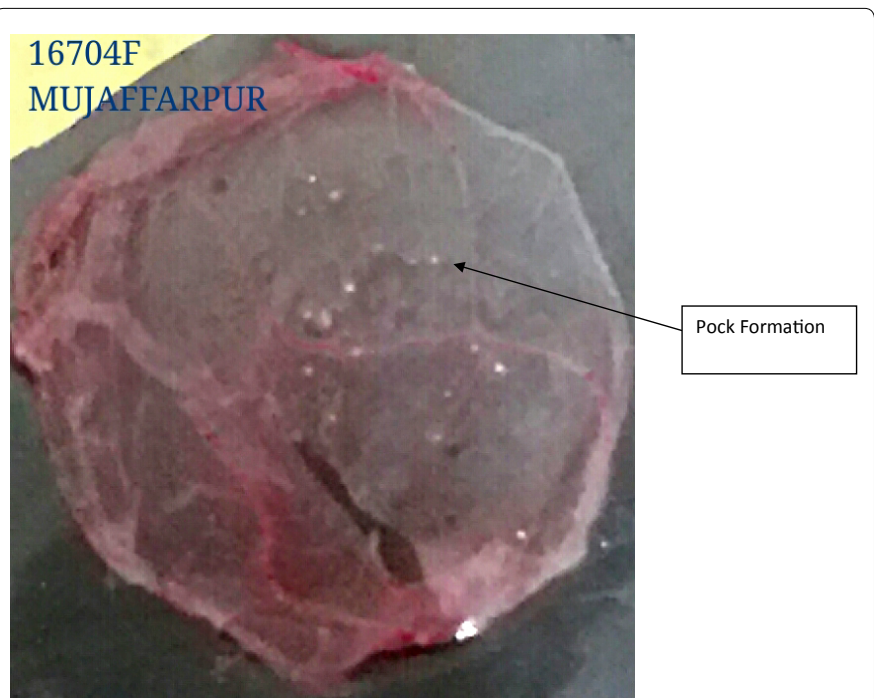

Figure 7: CSF sample collected from Muzaffarpur inoculated in CAM showing discrete pock formation (Pock Count 14-16).

maintenance IV fluids and supportive nursing care. The therapeutic response to dextrose was encouraging. Rapid clinical response was observed in patients with early initiation of dextrose infusion compared to those with late administration.

\section{Comparison between controls of litchi belt and non-litchi belt}

The team collected blood from healthy controls residing in same litchi belt of Malda from where cases emerged and from healthy controls residing in non-litchi producing belts of Malda. The controls were of same age groups as of cases and belonged to similar socio-economic condition also. Controls were free from any other minor illnesses

Fasting Blood glucose level were compared between 18 cases and 12 and 9 controls of litchi belt and non-litchi belt respectively. We estimated fasting blood sugar level from the same laboratory. 1 sample from non-litchi area showed a blood sugar level of $175 \mathrm{mg} \%$, hence excluded as outlier from the study. Independent $t$ test was carried out to compare the mean fasting blood glucose level of these two types of controls.

Serum SGPT and Sodium levels were compared between 19 cases and 7 controls of litchi belt and 9 controls from non-litchi belt. The data were analyzed in same way.

\section{Methods}

Epidemiological analysis included age distribution of cases, deaths along with calculation of age and specific case fatality rates. Time distribution of cases and deaths were plotted in line diagram. Also distribution of deaths was done according to time interval from their admission to death. Proportion of different clinical and pathological manifestations such as convulsion, fever, unconsciousness, decerebrate rigidity, hypoglycaemia, leucocytosis etc. was calculated. Overall the statistical analysis were performed by MS excel 2007 and SPSS (version $16)$.

\section{Results}

\section{Interpretations}

1) Risk of death is much higher in case of children below 5 years compared to those aged 5 years (Table 1).
2) Fasting Blood glucose level of cases were significantly lower than the controls (Table 2).

3) No significant difference was observed between SGPT level of cases and controls (Table 3 ).

4) Controls of litchi belt showed significantly lower level of fasting blood glucose level than the controls of non-litchi belt (Table 4).

5) Comparison of serum SGPT level (Table 5).

6) No significant difference found in Serum SGPT and Sodium levels between controls from litchi belt and non-litchi belt (Table 6).

\begin{tabular}{|c|c|c|c|}
\hline Age group (yrs) & Case & Death & Case Fatality Rate (\%) \\
\hline$<5$ & 51 & 29 & 56.9 \\
\hline$>=5$ & 20 & 5 & 25 \\
\hline
\end{tabular}

Chi sqr $=5.84, \mathrm{df}=1, \mathrm{p}=0.01$, Relative Risk $=2.27(95 \% \mathrm{Cl}: 1.03-5.04)$

Interpretation: - Risk of death is much higher in case of children below 5 years compared to those aged 5 years and above.

Table 1: Comparison of Case Fatality Rate (\%) between $<5$ and $>=5$ years age groups.

\begin{tabular}{|l|c|c|c|c|c|}
\hline & case-control & $\mathbf{N}$ & Mean & Std. Deviation & Std. Error Mean \\
\hline blood glucose(F) & case & 18 & 41.83 & 28.480 & 6.713 \\
\hline & control & 12 & 58.08 & 11.301 & 3.262 \\
\hline
\end{tabular}

$\mathrm{t}=2.17, \mathrm{df}=23.91 \#, \mathrm{p}=0.04$

\# Equal variance not assumed as per the result of Levene's Test for Equality of Variances

Interpretation:- Fasting Blood glucose level of cases were significantly lower than the controls

Table 2 : Comparison of fasting blood glucose level between cases and controls of same areas (litchi belt).

\begin{tabular}{|l|c|c|c|c|c|}
\hline & case control & N & Mean & Std. Deviation & Std. Error Mean \\
\hline serum SGPT & case & 19 & 39.95 & 19.196 & 4.404 \\
\hline & control & 7 & 25.71 & 9.160 & 3.462 \\
\hline
\end{tabular}

$\mathrm{t}=1.86, \mathrm{df}=24, \mathrm{p}=0.07$

Interpretation:- No significant difference was observed between SGPT level of cases and controls

Table 3 : Comparison of serum SGPT level between cases and controls of same areas (litchi belt).

\begin{tabular}{|l|c|c|c|c|c|}
\hline & type of control & N & Mean & Std. Deviation & Std. Error Mean \\
\hline $\begin{array}{l}\text { fasting blood } \\
\text { glucose }\end{array}$ & non litchi control & 8 & 87.50 & 16.239 & 5.741 \\
\hline & litchi control & 12 & 58.08 & 11.301 & 3.262 \\
\hline
\end{tabular}

$t=4.76, d f=18, p=0.000$

Interpretation: -

Controls of litchi belt showed significantly lower level of fasting blood glucose level than the controls of non-litchi belt.

Table 4 : Comparison of fasting blood glucose level between controls of litchi belt and non-litchi belt.

\begin{tabular}{|l|c|c|c|c|c|}
\hline & type of control & N & Mean & Std. Deviation & Std. Error Mean \\
\hline serum SGPT level & non litchi control & 9 & 29.89 & 11.900 & 3.967 \\
\hline & litchi control & 7 & 25.71 & 9.160 & 3.462 \\
\hline
\end{tabular}

$\mathrm{t}=.766, \mathrm{df}=14, \mathrm{p}=0.456$

Table 5 : Comparison of serum SGPT level between controls of litchi belt and non-litchi belt. 


\begin{tabular}{|l|c|c|c|c|c|}
\hline & type of control & $\mathbf{N}$ & Mean & Std. Deviation & Std. Error Mean \\
\hline $\begin{array}{l}\text { serum sodium } \\
\text { level }\end{array}$ & non litchi control & 9 & 138.00 & 2.784 & .928 \\
\hline & litchi control & 7 & 138.57 & 2.299 & .869 \\
\hline
\end{tabular}

$\mathrm{t}=0.438, \mathrm{df}=14, \mathrm{p}=0.668$

Interpretation: -

No significant difference found in Serum SGPT and Sodium levels between controls from litchi belt and non-litchi belt.

Table 6 : Comparison of serum sodium level between controls of litchi belt and non-litchi belt.

\section{Discussion}

Central Nervous System (CNS) infections remain some of the most challenging diseases to diagnose and treat and a wide range of agents can cause these diseases. An infectious cause of encephalitis was determined in less than $30 \%$ to $40 \%$ of cases worldwide and rest of them remain unknown. Significantly, this difficulty remains even in the era of polymerase chain reaction (PCR)-based approaches to the diagnosis of CNS infections, particularly of encephalitis. Rapid and accurate detection of agents in CNS infections is crucial to improving diagnosis and providing the best therapies for patients.

CNS infections impose a substantial burden on the healthcare system. Moreover, the changing epidemiological patterns of arboviral CNS infections may have profound implications on both a local and global scale. The incidence of CNS infections varies by geographic region, and many risk factors for CNS infections remain unclear, particularly for infections of unknown cause.

CNS infections are potentially fatal diseases caused by a wide variety of pathogens including bacteria, viruses, fungi and parasites. CNS infections can also occur sporadically, endemically (e.g., arboviruses), or in outbreaks (e.g., Nipah virus) [6-8].

Seasonal outbreaks of acute encephalitis syndrome (AES) occur with striking regularity in India and lead to substantial mortality. However, the landscape of AES in India has changed in the previous decade, and both outbreak investigations and surveillance studies have increasingly reported non-JEV aetiologies. While most studies from 1975 to 1999 identified JEV as the main aetiological agent for AES in India, many studies published after 2000 identified Chandipura and enteroviruses as the most common agents, in both outbreaks and surveillance studies [9].

Since the summer of 2012, unexplained outbreaks of acute encephalitis in children coinciding with litchi (Litchi sinensis) harvesting (precisely the month of June) have occurred in the Kaliachak Block of Malda District in West Bengal. Similar outbreaks were also reported from Muzaffarpur district of the neighbouring state of Bihar. Interestingly both these areas are litchi growing areas of the states and the outbreaks occur typically during the litchi harvesting season of the year $[10,11]$. It was thought that Malda AES was Japanese encephalitis (JE), which is widely prevalent in India; however, JE was ruled out. Similar unexplained outbreaks of non-JE acute encephalitis have been documented in northern Vietnam [12] and Bangladesh [13] co-incident with the litchi harvesting season. These outbreaks are unusual because of their specific location (litchi growing belts), their strict seasonality (during May-July), the restricted age group of persons at risk $(<10$ years old), and the clinical features (abrupt onset of convulsions, rapid progression to coma). The clinical, biological, and immunologic characteristics of the patients suggests a viral etiology. But unfortunately no viruses could be isolated nor detected by molecular methods in the samples collected from both Malda and Muzaffarpur AES cases in the previous years. Also inconclusive virological tests results were reported from the Vietnam study [12].

Not surprisingly several studies explored other possibilities regarding the causation of the disease. One study concluded that the disease was not due to infection, but was due to heat stroke [10] while investigators from Bangladesh [13] attributed the disease to pesticides. Another study hypothesised that Muzaffarpur AES was caused by a toxic substance methylenecyclopropyl -alanine (MCPA), also called hypoglycinA present in the litchi fruit [11].

Sometimes an acute encephalopathy may be clinically indistinguishable from encephalitis of viral aetiology. CSF study helps. But overlapping in CSF picture showing normal cell with mildly raised protein, may fail to differentiate. The notable encephalopathy reported as both sporadic cases and also as outbreaks is the Reye encephalopathy [14]. Typically Reye syndrome follows influenza or chicken pox attacks and precipitated by intake of aspirin. We found no such history from the affected cases. However it can be precipitated by chemicals like insecticides also, which are used in litchi cultivation particularly during harvesting. The hallmark of Reye syndrome is raised liver enzymes. We got mildly raised liver enzymes only in 5 cases. Thus, it can be concluded that the whole outbreak was not due to Reye encephalopathy.

The investigators of this study, report for the first time that the evidence gathered so far points towards a viral etiology. Herpes viruses and JE virus are known for causing AES as well as producing pocks in CAM of embryonated eggs. But PCR studies for both JE and Herpes viruses were negative among the CSF samples collected from Malda AES cases. The causative virus has remained unidentified and may be responsible for unexplained acute encephalitis elsewhere in the world, particularly in regions sharing similar ecology and environment. As of now, it can be concluded that the virus can be a previously unrecognized virus as a causative agent for AES or a novel pathogen which has emerged due to globalization, climate change, and environmental encroachment, and pose important diagnostic challenges $[15,16]$.

Further studies using high throughput sequencing technology and resequencing micro-arrays are required for identication and characterization of the incriminating virus [17-19]. These tests can be performed on serum, CSF, culture supernatants, and brain homogenates from suckling mice inoculated intracerebrally with patients' CSF. Although electron microscopy of brain tissue is a standard method of identifying new viral pathogens in encephalitis syndromes, we were unable to obtain brain tissue specimens through autopsy because of socio- cultural barriers. The association between litchis and acute encephalitis remains unclear. As with other emerging viruses, we face a multifactorial problem that seems to have litchi fruit production and harvest as its focal point. One possible scenario is that fruit-bearing litchi trees can attract bats, which might be the reservoir for the putative pathogen $[10,20]$. Since cases have significantly lower level of blood glucose it may appear that hypoglycaemia induced by consumption of litchi fruit and overnight fasting may lead to onset of early morning seizures in children of such age group. But in the study of controls we found significantly lower level of blood glucose in the control children of litchi belt compared to those of non-litchi belt. Hence we hypothesize that hypoglycaemia induced by litchi fruit may have aggravated the encephalitis rather than actually causing it.

\section{Conclusion}

Recurrent unexplained outbreaks of acute encephalitis in children coinciding with litchi harvesting season have been reported from India (West Bengal and Bihar), Vietnam and Bangladesh. Although the 
Citation: Bandyopadhyay B, Chakraborty D, Ghosh S, Mishra R, Rahman M, et al. (2015) Epidemiological Investigation of an Outbreak of Acute Encephalitis Syndrome (AES) in Malda District of West Bengal, India. Clin Microbial 4: 181. doi:10.4172/2327-5073.1000181

clinical, biological, and immunologic characteristics of the patients suggests a viral etiology, the causative agent could not be ascertained in each of the outbreaks, As a result several hypothesis have been put forward namely heat stroke, pesticides or hypoglycin A as the cause of the AES syndrome. The investigators of this study, report for the first time that the evidence gathered so far points towards a viral etiology. The causative virus has remained unidentified and further studies using high throughput sequencing technology and resequencing micro-arrays are required for identification and characterization of the incriminating virus. Also the hypoglycaemia induced by litchi fruit may have aggravated the encephalitis rather than actually causing it.

\section{Conflict of Interest}

All authors declare that there is no conflict of interest

\section{Authors` Contribution}

1. BB conceptualized the whole study, participated in the design of the microbiological part, performed laboratory experiments, drafted and revised the manuscript critically.

2. DC participated in the design of epidemiological portion, performed statistical analysis, drafted and revised the manuscript critically.

3. $\mathrm{NB}_{1}, \mathrm{DM}$ and $\mathrm{RM}, \mathrm{NB}_{2}$ conceptualized the study, participated in the design of microbiological and epidemiological portion, facilitated the overall study activities and revised the manuscript critically

4. SG, NM and MA participated in the design of clinical portion, analyzed clinical data and revised the manuscript critically.

5. SA, $\mathrm{AM}_{1}$ and DKM helped in coordination, collected clinical \& epidemiological data, clinical and control samples and facilitated the overall study activities

6. $\mathrm{AD}, \mathrm{AM}_{2}, \mathrm{AKM}, \mathrm{AK}$ performed clinical diagnosis and treatment of cases, collected clinical data and clinical samples, helped in clinical data analysis.

7. SH helped in collection of clinical and control samples and assisted the laboratory experiment

All authors read and approved the final manuscript.

\section{Acknowledgement}

We sincerely acknowledge the continuous support of Department of Health and Family Welfare, Government of West Bengal, for successfully conducting the study. We also express our gratitude to Director NIV Pune, Dean NIMHANS and their team for conducting the molecular viriological and other microbiological testing of the clinical samples for AES.

\section{References}

1. Solomon T, Thao TT, Lewthwaite P, Ooi MH, Kneen R, et al. (2008) A cohor study to assess the new WHO Japanese encephalitis surveillance standards. Bull World Health Organ 86: 178-186.

2. Jmor F, Emsley HC, Fischer M, Solomon T, Lewthwaite P (2008) The incidence of acute encephalitis syndrome in Western industrialised and tropical countries. Virol J 5: 134.

3. Gendelman HE, Persidsky Y (2005) Infections of the nervous system. Lancet Neurol 4: 12-13.
4. Geevarghese G, Kanogia PC, Mishra AC (2004) Japanese encephalitis-Vector Biology. NIV Pune Year Book. Orient Longman Publication, Himayatnagar 335356.

5. Guidelines clinical management of acute encephalitis syndrome Including japanese encephalitis Government of India Directorate of national vector borne disease control programme.

6. Gurley ES, Hossain MJ, Paul RC, Sazzad HM, Islam MS, et al. (2014) Outbreak of hepatitis $E$ in urban bangladesh resulting in maternal and perinatal mortality. Clin Infect Dis 59: 658-665.

7. Bhaswati Bandyopadhyay, Indrani Bhattacharyya, Srima Adhikary, Saiantan Mondal, Jayashree Konar, et al. (2013) Incidence of Japanese Encephalitis among Acute Encephalitis Syndrome Cases in West Bengal, India. BioMed Research International 2013: 1-5.

8. Arankalle VA, Bandyopadhyay BT, Ramdasi AY, Jadi R, Patil DR (2011) Genomic characterization of Nipah virus, West Bengal, India. Emerg Infect Dis 17: $907-909$

9. Chadha MS, Comer JA, Lowe L, Rota PA, Rollin PE, et al. (2006) Nipah virusassociated encephalitis outbreak, Siliguri, India. Emerg Infect Dis 12: 235-240.

10. Joshi R, Kalantri SP, Reingold A, Colford JM Jr (2012) Changing landscape of acute encephalitis syndrome in India: a systematic review. Natl Med J India 25: $212-220$.

11. Dinesh DN (2013) Possible factors causing Acute Encephalitis Syndrome outbreak in Bihar, India. Int J Curr Microbiol App Sci 2: 531-538.

12. John TJ, Das M (2014) Acute Encephalitis Syndrome in children in Muzaffarpur: hypothesis of toxic origin. Current Science 106: 1184-1185.

13. Paireau J, Tuan NH, Lefrançois R, Buckwalter MR, Nghia ND, et al. (2012) Litchi-associated acute encephalitis in children, Northern Vietnam, 2004-2009. Emerg Infect Dis 18: 1817-1824.

14. Islam MS (2013) In Annual Meeting of the American Society of Tropical Medicine and Hygiene, 940.

15. John TJ (2003) Outbreak of killer brain disease in children: mystery or missed diagnosis? Indian Pediatr 40: 863-869.

16. Dong J, Olano JP, McBride JW, Walker DH (2008) Emerging pathogens: challenges and successes of molecular diagnostics. J Mol Diagn 10: 185-197.

17. Jones KE, Patel NG, Levy MA, Storeygard A, Balk D, et al. (2008) Global trends in emerging infectious diseases. Nature 451: 990-993.

18. Benjamin LA, Lewthwaite P, Vasanthapuram R, Zhao G, Sharp C, et al. (2011) Human parvovirus 4 as potential cause of encephalitis in children, India. Emerg Infect Dis 17: 1484-1487.

19. Le Van Tan, Rogier van Doorn H, Ho Dang Trung Nghia, Tran Thi Hong Chau, Le Thi Phuong Tu, et al. (2013) Identification of a New Cyclovirus in Cerebrospinal Fluid of Patients with Acute Central Nervous System Infections, mBio 4: e00231-13.

20. Cheval J, Sauvage V, Frangeul L, Dacheux L, Guigon G, et al. (2011) Evaluation of High-Throughput Sequencing for Identifying Known and Unknown Viruses in Biological Samples. J Clin Microbiol 49: 3268-3275.

21. Calisher CH, Childs JE, Field HE, Holmes KV, Schountz T (2006) Bats: important reservoir hosts of emerging viruses. Clin Microbiol Rev 19: 531-545. 